\title{
Los (as) Adolescentes Hablan De Paternidad y Maternidad en Cartagena de Indias: Casos Santa lucía y Ceballos
}

\author{
Por: Carmen Cecilia Alvear Romero \\ Elda Herazo Dilson
}

\section{RESUMEN}

información mayor Yolanda Puyana $\mathrm{V}$ i l l a m i z a r (Compiladora), 2003, Padres y madres en cinco ciudades colombianas, cambios y permanencias. CONETS, Universidad Nacional, Universidad del Valle, UNAB, Universidad Cartagena Universidad Antioquia.

${ }^{2}$ Los dibujos fueron analizados en función de cada contexto (Santa Lucía / C e ballos ) específico, relato $y$ situación familiar en particular del (la) Joven, a diferencia de la perspectiva Psicológica con la que común y tradicionalmente ha sido usada esta técnica, pues no se trataba de identificar patologías Psicológicas, ni mucho menos analizar clínicamente cada joven, sus posibles $\mathrm{n}$ e c e s i d a d e s inconscientes, conflictos y rasgos de personalidad. La aplicación de esta técnica, fuè mas una estrategia que permitiera hacer visible lo invisible, o en su lugar ratificar lo dicho en los relatos.
El presente artículo hace una reflexión en torno a las demandas de cambio en el ejercicio de la Maternidad y Paternidad a partir de las representaciones sociales que sobre estas funciones parentales realizan hijos e hijas adolescentes en la ciudad de Cartagena, casos Santa Lucia y Ceballos. Develar las voces y significaciones de los(as) jóvenes frente a categorías como autoridad, afectividad y división sexual de roles en el hogar, es una oportunidad para potenciar a esta población como protagonistas de nuevas formas de relación e interacción familiar y social, que complementa los tradicionales esquemas de entender e intervenir el sistema familiar.

\section{Presentación}

\section{$\square$ n Colombia han mantenido relevancia los estudios sociales sobre la Familia, diversos autores(as) e investigadores(as), entre ellos Virginia Gutiérrez de Pineda, Gloria Calvo, Ligia Echeverry Ángel, Hernán Henao Delgado, María Cristina Palacios, y Yolanda Puyana entre otros, han dado cuenta de la complejidad, evolución, diversidad y características culturales de la familia.}

En reconocimiento a experiencias y conocimientos acumulados en el tema, y enmarcados en investigaciones mas recientes como aquella de carácter nacional realizada desde 1999 hasta 2001 denominada: "Cambios en las Representaciones Sociales de la Paternidad y la Maternidad", el caso de Bogotá, Cali, Medellín, Bucaramanga y Cartagena; se concibió el texto que a continuación se presenta, como resultado de un proceso de investigación de corte cualitativo, desarrollado desde el grupo de Investigación Estudios de Familia, Masculinidades y Feminidades, de la Facultad de Ciencias Sociales y Educación de la Universidad de Cartagena. En el se analiza, a partir de entrevistas a profundidad y los Dibujos de la Figura Humana (DFH), ${ }^{2}$ las demandas de cambio en torno al ser Padre y Madre desde 
la perspectiva de los hijos e hijas en la ciudad de Cartagena, contextualizada en los barrios Santa Lucía y Ceballos de la Localidad Industrial y de la Bahía. Dos realidades socioeconómicas y culturalmente distintas, dos formas diferentes en que sus habitantes conciben y organizan sus espacios y la red de relaciones y poder que allí se tejen.

Bajo estas diferencias contextuales y transversalizadas por la categoría de género, estas líneas dan cuenta de la tradicionalidad con que hoy día los(as) jóvenes conciben la paternidad y maternidad, pero también de las demandas de cambio que reclaman desde el ejercicio de la autoridad, la afectividad masculina y las relaciones de genero en la familia. Demandas que aun no están impactando su práctica cotidiana.

\section{Por qué Indagar desde los (as) Jóvenes?}

Tanto la Paternidad como la Maternidad son categorías socialmente elaboradas, compartidas y aprendidas en la vida diaria, sin embargo su ejercicio va evolucionando y transformando en diferentes etapas del desarrollo individual y familiar, cada momento en la vida de las personas requieren nuevas demandas que presionan las relaciones entre padres, madres e hijos(as) para acomodarse a innovadoras maneras de asumir estas funciones.

Las relaciones parentofiliales ${ }^{3}$ se construyen y cambian a medida que se produce el crecimiento de los hijos(as) y la maduración de los padres. En las relaciones entre padre, madre e hijos(as) están en juego un sin número de necesidades, intereses $y$ afectos diferentes que en un momento dado pueden entrar en contradicción, y esto se hace mas evidente cuando los(as) hijos son adolescentes, ya que ellos(as) confrontan las normas, hacen resistencia a la acción disciplinaria de la familia y en ocasiones llegan a chocar con el dominio afectivo de los padres. En la cotidianidad los hijos(as) adolescentes se enfrentan a nuevas exigencias y valores que el medio ofrece en las diferentes posibilidades de interacción con los otros, con frecuencia los avances científicos y tecnológicos, el trabajo, la calle, los (as) amigos(as), los medios masivos de comunicación y educación, entre otros, son los contextos que reafirman valores y principios, pero al mismo tiempo generan conflictos y contradicciones que van alterando las prácticas en el hogar

y las representaciones acerca de Padres y Madres en los(as) hijos(as), generando cambios, que en algunos casos se dan lentamente y de forma gradual, y en otros de manera rápida y sustancial. Estas situaciones ocurren en el sistema familiar con las influencias del medio económico, social y cultural en el que se está inmerso y del que recibe patrones e influencias, reflejados en el interior de la

3 Se refiere a los vínculos afectivos y a las relaciones de poder que se establecen entre padres, madres e hijos(as) ya sea por lazos de consanguinidad $\mathrm{O}$ afinidad. En: JIMENEZ ZULUAGA, Blanca Inés, 2003, Conflicto y Poder en Familias con Adolescentes: Medellín y Cartagena. Universidad de Antioquia, Centro de Investigaciones Sociales y Humanas, y Fundación para el Bienestar Humano. Pag. 22 
familia en la forma como padres, madres e hijos(as) manifiestan expresiones de afecto, formas comunes de relación y comunicación, en el ejercicio de la autoridad y en la forma como se asumen los roles sexuales

\section{Padre, Madre e Hijo(a): Roles y Funciones que se Conciben en la Tradición}

Las funciones parentofiliales conservan en el imaginario juvenil la tradicional acepción por género, donde madre es sinónimo de sacrificio y amor, y tanto el padre como el hijo(a) son funciones relacionadas a la responsabilidad que representa para unos la manutención de un hogar y para otros responder al compromiso y sacrificio económico y afectivo que realizan padres y madres.

Para los y las jóvenes la maternidad es una función inherente a la condición femenina, sobrevalorada por la protección y la fuerte relación afectiva que los une, indistintamente si es una mujer dedicada exclusivamente al hogar o aquella que comparte sus funciones de madre con las de profesional; con frecuencia se hace referencia a ella resaltando su tarea fundamental en la gestación, y en este sentido, se puede decir que los relatos tienden a reafirmar expresiones como "en el inconsciente colectivo sigue vigente la idea de que la crianza es ante todo asunto de mujeres, que el padre es mas bien su colaborador y no un socio de igual nivel, y por último que su participación es menos necesaria, o si se quiere mas accesoria". ${ }^{4}$ Algunos relatos así nos lo muestran:

"El significado de madre es más que el del padre, es la que te alimenta cuando tu estás adentro, cuando tienes hambre, más que todo el papá no se pone en eso." (Diego, 17 años -SL)

"Ser madre para mi, es una mujer luchadora, una mujer que solo vive por sus hijos, una mujer que brinda mucho amor, que valora mucho lo que tiene, una mujer que se esmera por sus hijos, que todo lo que hace lo hace por amor a sus hijos". (Yajaira, 15 años $-C$ )

La paternidad es una función que el y la joven centran en la "responsabilidad económica", lo que genera seguridad en la medida que provee los insumos básicos

${ }^{4}$ Badinter Elizabeth, 1991 ¿Existe el Instinto Maternal? Historia del amor maternal, siglos XVIII al XX, ediciones Paidós Pag. 240 para el bienestar de la familia, diferenciándose el referente de bienestar según las posibilidades económicas, así, en Santa Lucía son mayores las aspiraciones y demandas económicas a la figura paterna. Los siguientes relatos dan cuanta de esta situación. 
"Ser papá es querer a uno, darle lo que uno necesita, lo del colegio y todo eso." (Oscar, 12 años $-C)$

"Ser papá, es como la fuerza, de pronto yo veo papá como algo más de que, lleva el dinero a la casa y que la mantiene, pero de pronto no es tan constante tan necesario como una madre, si es necesario pero la mamá le enseña mas cosas". (Sandra, 14 años $-S L)$

Sobre la categoría de hijo(a), solo algunos(as) jóvenes en Santa Lucía se refirieron a esta condición cuestionando la relación de dependencia y autoridad frente a las figuras paternas y maternas, aun cuando en la adolescencia la mayoría de los conflictos están asociados con la etapa de cambios y cuestionamientos por la cual los(as) jóvenes atraviesan, "un periodo de contradicciones, confuso, ambivalente, doloroso, caracterizado por fricciones con el medio familiar y social" ${ }^{5}$

Estos son los relatos de los(as) jóvenes de Santa Lucia:

"Ser hijos, es pues privarse de cosas, porque ellos (los padres) son los que nos dan a nosotros." (karen, 14 años-SL)

"Es el deber de reclamarle a mis papás, de hacerles caer en cuenta de sus errores, el aprender de todos un poquito" (Sandra, 14 años - SL)

"Es como estar en una constante de diferentes pensamientos" (Victor, 15 años - SL)

Para los y las jóvenes de Ceballos, ser hijos(as) es un concepto normatizado, asociado a la obediencia y la responsabilidad, la prolongación de los padres, como lo muestra el relato de Yenifer:

“Un hijo significa mucho pa' las madres porque como dicen de pronto sea el hijo mío el que me vá a sacarme el pié del barro, porque uno no sabe mañana o pasao pa'qué le vá a servirle su hijo a uno, porque usted puede tener su esposo, vamos a poné, y su esposo se le vá, y quien le queda a usted es su hijo, quien va a vé por usté es su hijo, usté va a está viejito y quien va a ver por usté es su hijo".

La concepción "Hijo(a) como garantía" que predomina en los relatos, contrasta con los actuales planteamientos que conciben al hijo(a) "como sujeto de derechos y obligaciones, derivado de un proceso cultural en el que interviene tanto el padre como la madre, y que significa que la dependencia filial no puede ser

${ }^{5}$ Aberasturi, Arminda «El adolescente y la libertad", en: conflicto y Poder en familias con adolescentes, Blanca Inés Jiménez Zuluaga, 2003 Pag 27. 
considerada jamás como una disposición instrumental de los padres sobre los hijos" ${ }^{6}$ pues se mercantilizaría la relación.

Tanto en Santa Lucia como en Ceballos prevalece la elaboración de la categoría de hijo(a) a partir del referente de padre y madre, es decir, el rol de hijo(a) solo es visible si se piensa y/o asume la función paterna y materna. En los relatos de estos(as) jóvenes no existe una construcción del si mismo como un ser autónomo, el asunto de la autonomía se desdibujó con el discurso de la retribución, la garantía y la responsabilidad moral.

\section{Una Autoridad que Trasciende la Norma: Hacia una Autoridad Afectiva}

Con la autoridad en la familia se busca el establecimiento y reconocimiento de principios, valores y normas que favorezcan la convivencia y el crecimiento de sus miembros. Por lo general la sociedad adhiere a los padres la función normatizadora, que en la adolescencia tiende a ser mayormente cuestionada. Las entrevistas en Santa Lucìa y Ceballos muestran que en la práctica los y las adolescentes se enfrentan a un padre normatizador que ejerce poder económico, al que hay que obedecer por su condición de proveedor. Y una madre que ejerce autoridad en el ámbito de lo afectivo. Por tanto sus expresiones se diferencian según sexo desde el padre y la madre: el padre impone disciplina y normas, es la figura central en la autoridad, la madre aconseja y orienta, su autoridad es parcialmente ejercida.

En este contexto, las demandas de cambio en el ejercicio de la autoridad estuvieron dirigidas hacia su forma de expresión, los(as) jóvenes cuestionan:

- Los maltratos físicos y verbales como forma de relación en la pareja y entre padre - madre e hijos(as), es decir, se demanda un ambiente familiar donde prime la convivencia y no la violencia:

"Me gustaría cambiar las peleas que hay entre mi mamá y mi papá, porque ese ambiente no es el que se debe dar en una casa, y a mi eso me duele, frente a eso pienso que deberían hablar, de que se entendieran, las cosas no se dan gritando, a los animales son a los que se les grita, no a los humanos, tienen que hablar mas

6 Dimensiones sociológicas de la paternidad, Consultado en Junio 15 de 2005, disponible en: $\mathrm{h} \mathrm{t} \mathrm{t} \mathrm{p}: /$, www.geocities.com/ papa hijo $2000 /$ sociologo.html?200522 no gritar y eso lo he aprendido en el colegio" (Ricardito, 13 años-SL)

- Mayor protagonismo del padre en términos de calidad de tiempo, es decir, no solo se necesita un padre normatizador a modo "solo para un caso", este también ha de compartir más espacio con los y las hijos(as), y esta es una de 
las principales demandas en el ámbito de la afectividad.

"Me gustaría que mi papá algunas veces interviniera en las conversaciones que yo tengo con mi mamá, casi siempre los problemas los resuelvo con ella, él siempre llega cansado.... Eso me gustaría que cambiara, que mi papá interviniera un poco más y que prestara un poco mas de atención a los problemas de la casa" (Víctor, 15 años$S L)$

- Con menor presencia, las jóvenes reclaman una autoridad ejercida en términos de igualdad entre hijos e hijas y entre padre y madre. Aunque estas diferencias de género en el ejercicio de la autoridad son visibles en más de un relato, para la mayoría de los jóvenes entrevistados(as) se constituyen en una situación "normal" en función del hecho biológico de ser hombre y mujer:

"Prácticamente a nosotros los varones, los castigos así que digamos fuertes no son, a mi hermana sí le prohíben las salidas, porque ella apenas tiene 16 años" (Pablo, 17 años-SL)

Lo anterior confirma el pensamiento tradicional y culturalmente trasmitido de algunos padres y madres que son más abiertos con los varones porque consideran que deben tener mas libertad que los hombres, y en cambio controlan y restringen las posturas autónomas de las hijas, especialmente en lo que se refiere a sus relaciones interpersonales y al uso del espacio público.

Relatos como el de Yhajaira muestran un pensamiento progresista y de ruptura en términos de género en el ejercicio de la autoridad:

"Yo creo que ambos padres tienen que tener autoridad, ambos son cabeza de hogar, tienen que dar, así como ambos tienen que estar de acuerdo cuando van a dar alguna orden, sólo él no puede" (yhajaira, 15 años - C)

Si las representaciones sociales expresan un pensamiento constituido y constituyente: constituido en tanto que se transforman en productos que intervienen en la vida social como estructuras preformadas a partir de las cuales se interpreta la realidad, y constituyente no solo porque expresan lo social sino que se interviene en su elaboración (Ibáñez, 1990 Pág. 36) y que además, las nuevas interpretaciones de la practica social van a incidir a la vez en el cambio social, podemos entender entonces que estas demandas de cambio frente a las formas de autoridad están preformando una nueva representación social: "La 
${ }^{7}$ Op. Cit.

8 Badinter Elizabeth, XY La Identidad Masculina, Grupo editorial Norma, 1993 Pag. 265

9 Según Blanca Inés Jiménez, el poder en las relaciones sociales ha tenido diversas interpretaciones con autores como Max Weber y Michel Foucault; tomando como referencia a Weber señala que el poder en la familia y la autoridad como una forma de su ejercicio, está relacionado con factores como el dinero y la satisfacción de n e c e s i d a d e s económicas, asi como con la afectividad que vincula a padre, madre e hijos. Conflicto y poder en familias con Hijos adolescentes, Pág. 30. Op. Cit letra con sangre no entra", la autoridad en el hogar es asunto de entender y negociar intereses, y roles en función del sexo, que sin duda alguna presionará nuevas formas de relacionarse en la práctica social.

La autoridad como espacio de negociación no significa necesariamente que esta se diluya, por el contrario se está demandando que sea ejercida ahora por el padre y la madre, negociando con los(as) jóvenes temas cruciales que los afectan como el control de sus cuerpos y de sus espacios.

Particularmente con el padre se demanda una autoridad afectiva, donde se manifiesten sus sentimientos amorosos y se trascienda la autoridad centrada en la proveeduría económica, "un padre sin compromiso y emocionalmente distante de sus hijos es una figura socialmente construida, pero no biológicamente determinada, por lo que la figura del padre comprometido es una realidad que puede y debe construirse socialmente" ${ }^{7}$ Es el llamado hacia un nuevo padre, "el hombre reconciliado" en términos de Elizabeth Badinter, ${ }^{8}$ que participe activamente en los cuidados, protección y educación de los(as) hijos(as).

\section{Las Expresiones Afectivas y los (las) Adolescentes: Hacia una Afectividad Paterna Comunicada y Demostrada}

En las relaciones parentofiliales cobra importancia tanto el vinculo afectivo que se construye y en consecuencia la conducta de apego y la seguridad que unen al hijo (a) con su madre y/o su padre, como las estrategias de poder que se despliegan a partir del ejercicio de la autoridad, el dinero y las expresiones del afecto. ${ }^{9}$ Estas expresiones afectivas continúan diferenciándose en su práctica por ser de mucho contacto físico, (besos, abrazos) para con las jóvenes de Santa Lucía y Ceballos, mientras que para los jóvenes se asocia al diálogo y el cumplimiento de normas en el hogar:

"Muy cariñoso con nosotros, hablan con nosotros, son unas personas que se sientan con nosotros y nos dicen las cosas que están bien y que están mal" (Pablo, 17 años $S L)$

"Todos hablamos, cuando nos van a decir algo nos reúnen y nos dicen, no forman bulla ni nada de eso, a mi me dicen que no haga nada malo, ni salga a la calle a pelear" (Oscar, 12 años-C)

"Mis papás siempre me están abrazando" (karen, 14 años -SL) 
"Cuando me besan, me dan felicitaciones, por lo que me pasa a mi se ponen contentos ellos, me abrazan y me besan." (Yajaira, 15 años-SL)

"A diferencia de mi papá voy a tratar de ser mas juguetón con mis hijos, porque a mi papà nunca le han gustado los juegos, y pues yo voy a tratar de que lo que le guste a mis hijos me guste a mi" (Victor, 15 años -SL)

En Ceballos las demandas sobre las expresiones afectivas son mayores y más heterogéneas, se cuestiona no solo mayor presencia del padre, sino condiciones de equidad en su expresión entre hijos e hijas:

"Pa' mi mamá es mi hermano, yo no. Me siento acomplejada porque siempre son ellos a los que mas les dan las cosas, a mi no. Yo se lo digo a mi mamá, pero ella que no, porque él es el mayor y él es el que necesita apoyarlo y tu eres una mujer, y de aquí a un tiempo abres las piernas y te vas, ya no pasa mas nada.....Que cambiaría yo, pues las relaciones que hay entre padre a hijo y madre a hijo, no haría diferencias entre niño y niña porque todos dos son ser y no hay que admitirle a unos mas cosas que al otro. Yo también podría cambiar en muchos conceptos, en que no haya conflicto entre las dos diferencias que hay, porque yo lo he pasado bastante y no me gustaría que pasaran también lo mismo, o sea a todos dos los apoyaría en las cosas que necesitara" (Elena, 17 años-C)

El cuadro 1 señala las principales demandas de cambio en ambos contextos según la categoría expresiones afectivas. Se resalta en Santa Lucía ambientes de socialización afectuosos con marcada influencia de la madre y un padre proveedor, que hace demandar una mayor presencia en este campo de la figura paterna.

\section{Cuadro 1}

Principales Demandas de Cambio en las Expresiones Afectivas

$$
\text { Barrios Santa Lucía y Ceballos de la Ciudad de Cartagena }
$$

\begin{tabular}{|l|r|}
\hline \multicolumn{2}{|c|}{ Cambio en Afectividad } \\
\hline \multicolumn{1}{|c|}{ Santa Lucía } & \multicolumn{1}{c|}{ Ceballos } \\
\hline $\begin{array}{l}\text { Mayor expresión afectiva de la } \\
\text { figura paterna. }\end{array}$ & $\begin{array}{l}\text { Mayor expresión afectiva de la } \\
\text { Mayor comunicación con la figura } \\
\text { paterna. }\end{array}$ \\
& $\begin{array}{l}\text { Disminución de maltratos físicos y } \\
\text { verbales. }\end{array}$ \\
& $\begin{array}{l}\text { Expresiones afectivas iguales } \\
\text { entre hijos e hijas. } \\
\end{array}$ \\
& $\begin{array}{l}\text { Mejor manejo de conflictos de } \\
\text { pareja. }\end{array}$ \\
\hline
\end{tabular}

Fuente: Entrevistas a profundidad realizadas a 16 jóvenes residentes en los barrios Ceballos y Santa Lucía. Octubre 2004 - Marzo 2005 
Y consecuentemente con la presencia de maltratos al interior de su familia, se piensa en ello como uno de los aspectos que indudablemente mejorarían y no repetirían en su papel de padres:

"No repetiría con mis hijos los maltratos que me daban de pequeña. Me maltrataban demasiado porque yo he sido muy rebelde" (Elena, 17 años-C)

"No repetiría el pelear con mi mujer para que mis hijos no se perjudiquen, porque hay veces que uno pelea con la mujer y los niños se ponen a llorar y uno se pone mal porque ellos sienten dolor y uno sigue como si nada hubiese pasado" (Alberto, 15 años- C)

En Ceballos los y las jóvenes están mostrando su preocupación sobre lo significativo que es una buena relación entre padre y madre para la socialización y el sano desarrollo físico y emocional de los(as) hijos(as), que pasa por la capacidad de negociación y comunicación que se logren establecer en el sistema parento-filial.

Las demandas de los(las) jóvenes desde la afectividad señalan un importante cambio en la representación social que quien naturalmente està equipada para dispensar afecto es la madre. Representación que reclama padres sensibles, democráticos y solidarios, que no se avergüencen de expresar sus sentimientos abiertamente, mas allá de la "Mística Masculina que dice que un verdadero hombre debe ser fuerte, competitivo, exitoso en el trabajo y con las mujeres, valiente, arriesgado, autosuficiente y agresivo, calificativos que pueden estar en la base de las dificultades que exhiben los hombres en el acercamiento afectivo a sus hijos varones y constituyen un obstáculo al buen desempeño de la función paterna". ${ }^{10}$

Gráficamente el dibujo de "Sandra" intenta dar cuenta de esta demanda.

${ }^{10}$ Varela, Marta Susana, 1999, Niños violentos...Padres faltantes? Psicoanálisis, estudios feministas $y$ género. en http:// www.psicomundo.com/ foros/genero/ faltante.htm

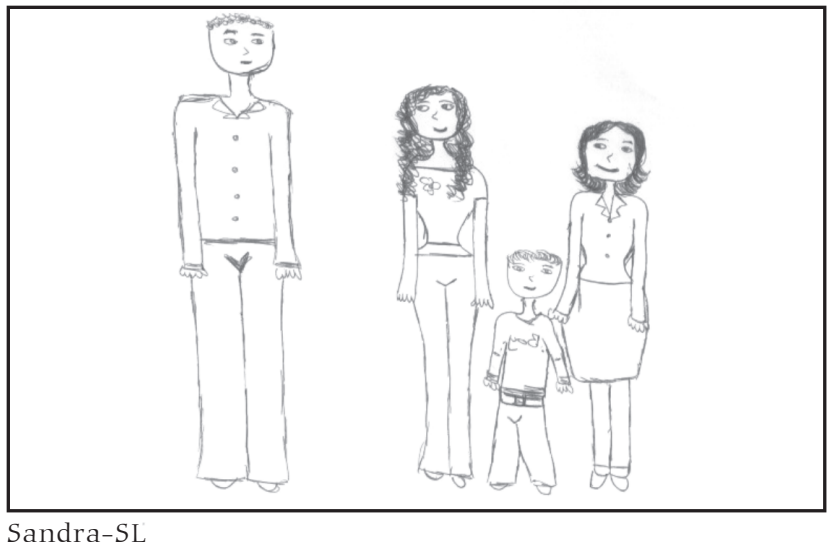

Sandra-SL 
Es preciso ratificar que en la investigación los dibujos fueron una forma de comunicación no verbal entre entrevistador(a) y entrevistado(a), y en este sentido Koppitz $^{11}$ señala que el dibujo es un lenguaje y puede analizarse al igual que el lenguaje hablado en diversas formas: a)se pueden evaluar en términos de su estructura, es decir, los detalles esperados normalmente en los dibujos a diferentes edades; b)los dibujos pueden ser analizados por su calidad, y por ultimo, c)se puede explorar el contenido de la producción grafica como un mensaje, sobre este último se sustenta el análisis hecho de los dibujos que los y las jóvenes realizaban complementariamente en cada entrevista, pues se trataba que el/la Joven lograra expresar y/o ratificar por medio del dibujo aquello que expresaron o no verbalmente

\section{La División Sexual de Roles en el Hogar: Una Demanda de Cambio de los (las) Adolescentes}

Bajo este subtitulo se indagó por la forma como los (las) jóvenes perciben y opinan sobre las labores domesticas en el hogar, la proveeduría, el apoyo en la escolaridad y la sexualidad, vistos estos descriptores desde las diferencias de hombre y mujer, para identificar sus principales demandas de cambio. Aunque el análisis arrojó que en esta categoría son menores las demandas de cambio, es importante resaltar que fueron enunciadas en su totalidad por las jóvenes tanto en Ceballos y como en Santa Lucía.

Para los jóvenes de Santa Lucía y Ceballos las labores domésticas son propias de las mujeres, a los hombres les compete principalmente la proveeduría económica, su apoyo a la domesticidad se asocia a tareas por fuera del hogar tales como "hacer los mandados," tarea que está desvinculada del espacio privado.

"Nosotros participamos aquí ayudando a componer el patio, ayudo cuidar los pollos, que no se pierdan. Nosotros nada mas hacemos los mandados" (Oscar, 12 año-C)

Aun cuando la figura materna participe activamente en la proveeduría, esta función no se resalta en sus relatos, donde los esfuerzos se centran en destacar esta función económica en el ejercicio de la paternidad. Al respecto reconoce una académica en el tema que"si bien la concentración de las tareas domésticas de forma exclusiva entre las mujeres a variado en los últimos años en Colombia, aun se presenta una inequitativa distribución de roles en el hogar". ${ }^{12}$

Así mismo, investigaciones recientes sobre juventud y género afirman que "en la mayoría de los países iberoamericanos persiste una determinación de

${ }^{11}$ Koppitz Elizabeth M. Evaluación Psicológica de los dibujos de la figura Humana por alumnos de educación media, editorial el manual moderno S. A. de C.V. México, D. F. , Santa Fè de Bogotá 1991, Pag. 13

12 Genero y Familia: Asociaciones Necesarias. Yolanda Puyana Villamizar, En revista Observatorio de asuntos de genero, Consejería presidencial para la equidad de la mujer y otros. Sep. Dic. 2004. Boletín $N^{\circ} 2$ Pag 6-8 
${ }^{13}$ Hopenhayn, Martín, La Juventud en I b e r o a m e ri c a : tendencias y urgencias, Naciones unidas Cepal-, Organización Iberoamericana de la Juventud, Santiago de Chile 2004, Pag. 96 roles en la familia que expresa subordinación de mujeres, contrastando los discursos que admiten un cambio importante en los papeles desempeñados por ambos sexos en relación con el trabajo, la familia y el cuidado de los(as) niños(as)" ${ }^{13}$

Para adentrarnos en el análisis de las demandas de cambio en las relaciones parentofiliales desde la perspectiva de género, es preciso anotar los contactos que desde uno y otro contexto pueden estar incidiendo en que las demandas fuesen hechas por las hijas. Encontrando que en las dos localidades las jóvenes están expuestas a diversos espacios de socialización, entre ellos los medios de comunicación, compartiendo y reconstruyendo información con su grupo de pares. En algunos casos se retomaron las experiencias personales como factor de reflexión sobre las prácticas sexuales maduras y responsables. Además, hay que tener en cuenta los cambios trascendentales del desarrollo Psicosexual propios en la adolescencia, que influyen en las formas de relación con el sexo opuesto, y con el mundo que les rodea.

En Santa Lucía los cuestionamientos a la categoría de género, estuvieron orientados a tres aspectos específicos: el tema de la sexualidad, en el sentido de un mayor dialogo con las hijas, la equidad de género en las relaciones parentofiliales (autoridad) y en el apoyo de las tareas escolares. (Ver cuadro 2) Sus relatos así nos lo muestran:

"Con mis hijos no repetiría el no hablar directamente de la sexualidad, me gustaría que mis hijos supieran todo desde chiquitos, que lo vieran como algo normal, no como algo prohibido" (Sandra, 14 años -SL)

"A mi me gustaría que la autoridad fuera igual, somos iguales o sea ni tan iguales porque yo soy la mayor y el (hermano) es menor dos años, y entonces no me gusta que si me va a dar una explicación que me de otra, pero no que "porque yo soy mujer". Yo esperaría que me dijera ya es muy tarde, no mira que ya nadie está allá bajo, es peligroso y entonces de igual manera a el (hermano) tampoco lo dejaran salir. Eso me gustaría cambiarlo, aunque yo no sienta que me afecta me podría afectar, porque eso va en contra de mi autoestima como mujer" (Karen, 14 años -SL)

"Recibo mas apoyo de mi primo que de mi mamá en las tareas escolares, me gustaría que cambiara, que los dos (papá y mamá) me ayudaran, porque es como un deber de ellos ayudarme" (Andrea, 13 años -SL) 


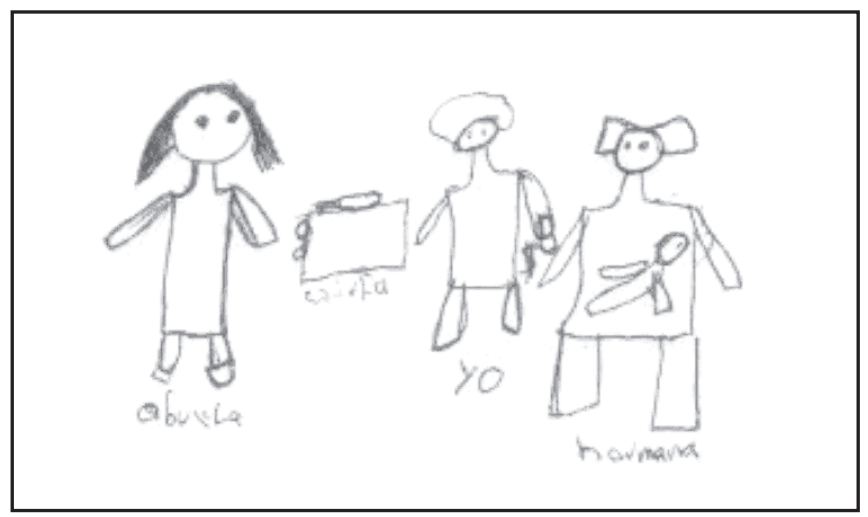

Oscar-C

En Ceballos las demandas de cambio relacionados con la equidad de género son expresadas en el tema de la autoridad, la domesticidad y la escolaridad:

"La crianza seria igual entre una hija y un hijo, porque si yo educo a uno de una forma y a otro de otra, no me gustaría, me gustaría tenerlos igual, que todos dos respetaran...No me parece bien que los hombres no hagan oficios, creo que ellos también deberán ayudar a las mujeres.." (Yamile, 13 años -C)

En este contexto barrial también se presentan demandas desde la sexualidad y una mayor libertad en la crianza de la mujer, puesto que a medida que los (las) hijos(as) crecen reclaman menos controles de los padres y luchan por tener mayor autonomía."La autonomía en los y las jóvenes se expresa básicamente en la toma de decisiones sobre su vida cotidiana y su futuro, en tener libertad para construir su propio mundo y en particular lo relacionado con las amistades, las salidas del hogar y el uso del tiempo libre". ${ }^{14}$

"A mis hijos(as) me gustaría darles un poquito mas de libertad, hacerlos mas libres, que ellos se den cuenta, aprendan a vivir también por si, o sea, porque uno necesita aprender cosas de la vida, y eso se aprende viviéndolas. Yajaira, 15 años- C)

"Yo le digo a las pelás, edda pelas ustedes cuídense, busquen cuidarse con algún método pa' ustedes tené relaciones, porque yo ya pasé por ahí y no quiero que ustedes pasen por ahí, ya yo tengo experiencia vivida" (Yenifer, 17 años, madre soltera-C)

Estos relatos y demandas de autonomía en las jóvenes están asociados a una mayor liberación de las mujeres con relación a su sexualidad, que lleva consigo la reconceptualización del discurso y las relaciones que hasta ahora le han significado a la mujer la pasividad sexual, la dependencia afectiva y la socialmente necesitada protección masculina. 
Cuadro 2

Principales Demandas de Cambio en la División Sexual de Roles al Interior de la Familia. Barrios Santa Lucía y Ceballos de la Ciudad de Cartagena

\begin{tabular}{|l|r|}
\hline \multicolumn{2}{|c|}{ Cambio en División de Sexo, Género y Roles } \\
\hline \multicolumn{1}{|c|}{ Santa Lucía } & \multicolumn{1}{|c|}{ Ceballos } \\
\hline $\begin{array}{l}\text { Comunicación abierta de la } \\
\text { sexualidad por parte de padre y } \\
\text { madre. }\end{array}$ & $\begin{array}{l}\text { Equidad de gé nero en la practica } \\
\text { de la autoridad. }\end{array}$ \\
$\begin{array}{l}\text { Equidad de género en la practica } \\
\text { de la autoridad. }\end{array}$ & $\begin{array}{l}\text { Equidad de genero en las labores } \\
\text { domesticas y apoyo de padre y } \\
\text { madre en las tareas escolares. } \\
\text { Apoyo de padre y madre en las } \\
\text { tareas escolares. }\end{array}$ \\
& $\begin{array}{l}\text { Mayor libertad en la crianza de la } \\
\text { mujer. }\end{array}$ \\
& $\begin{array}{l}\text { Practica sexual responsable en la } \\
\text { adolescencia. }\end{array}$ \\
& \\
\end{tabular}

Fuente: Entrevistas a profundidad realizadas a 16 jóvenes residentes en los barrios Ceballos y Santa Lucía. Octubre 2004 - Marzo 2005

En función a la categoría de género quienes están planteando nuevas formas de relación son las jóvenes, que se pueden estar sintiendo más afectadas y controladas, especialmente en el ejercicio de la autoridad, y la sexualidad. Frente a este ultimo continua existiendo tabú en las familias de los y las jóvenes entrevistados(as), en ambos barrios es muy poca la información que reciben al respecto por parte del padre y la madre. En general sobre la sexualidad se comenta y comparte información con amigos(as), con quienes hay un ambiente de más confianza e informalidad, con quienes se "normaliza" el tema.

La sexualidad ha sido uno de los mayores temores de los padres en la socialización de las hijas por las representaciones sociales que prevalecen en las sociedades actuales, condicionadas por razones históricas, sociales, económicas y culturales, que consideran que el fin de la vida de la mujer es el matrimonio y la maternidad, por tanto, "el proceso de socialización en la familia y en otras instancias se dirige a formar a la niña en torno a este rol, resaltando los valores que garantizan su capacidad de servicio a los demás y reprimiendo su sexualidad". ${ }^{15}$ Hoy coexiste esta tradicional representación social de la mujer junto a los nuevos roles adquiridos por ella con la conquista de su espacio social. Este desfase entre las expectativas sociales y las personales es un conflicto que puede estar presente en las adolescentes, que por la condición de mujer y la socialización hacia el ejercicio de su rol, son un blanco mayoritario de conflictos y tensiones. Por un lado se encuentran los padres controlando los movimientos

15 Op. Cit. Puyana Villamizar, Yolanda, Pág. 25-38 de las jóvenes en el espacio publico, ante el temor de que su trato con el sexo masculino ocasione un embarazo o alguna enfermedad de transmisión sexual; 
y por otro lado están las jóvenes reclamando autonomía y tratando de reafirmar su identidad.

En la relación género, como construcción social de la sexualidad, y las relaciones parentofiliales, el proceso de conocer y respetar las necesidades de los(as) jóvenes, el dialogo, el compromiso, la confianza y la participación activa entre padres e hijos(as), son fundamentos esenciales para que los y las adolescentes reafirmen identidad, construyan sanas relaciones con los otros, y en ultimas sean los verdaderos sujetos de su propia educación, con autonomía y plenas posibilidades para decidir responsablemente su camino, sin que los padres les impongan sus ideas y sentimientos, ni ocupen el espacio que a ellos(as) le corresponde como personalidades únicas e irrepetibles.

\section{Algunas Conclusiones...}

La investigación permitió establecer que son las jóvenes tanto de Santa Lucía como de Ceballos las que empiezan a cuestionar una mayor equidad de género en el ejercicio de la autoridad, en la sexualidad y la domesticidad, sin que estos cuestionamientos trasciendan o impacten sus prácticas cotidianas. Los jóvenes por su parte, continúan reproduciendo en sus relatos la tradicional representación social de mujeres en la casa y hombres en la calle.

En las expresiones afectivas son reiterativas las demandas tanto en uno como en otro contexto de una mayor cercanía paterna, es decir, una mayor comunicación y contacto físico entre padre e hijos(as). Demandas que tampoco están impactando la cotidianidad en sus relaciones parentofiliales.

La sexualidad fue una categoría emergente, que permitió acercarnos a las representaciones sociales de los (las) adolescentes sobre el tema, y si bien las Jóvenes de Ceballos mostraron una postura mas abierta, demandando practicas sexuales responsables, en el grueso de los y las entrevistados(as) sigue siendo un tema tabú y poco conversado al interior de la familia.

En general los y las jóvenes de Ceballos están cuestionando y demandando más cambio en el ámbito de las relaciones parentofiliales, pero frente a sus actuales y precarias condiciones sociales y económicas de socialización, cabe preguntarse si podrán movilizar y materializar sus demandas de cambio con las tensiones que están generando sus espacios de socialización a nivel comunitario y familiar. Contextualmente caracterizados por el ocio y la diversión en torno a los picku'p, concebidos estos en el ámbito familiar como 
factor de riesgo para la población juvenil en cuanto a la sexualidad femenina, el pandillismo, la drogadicción y la delincuencia. El cerrar esta brecha entre expectativas y logros en la población juvenil es uno de los principales retos que debe asumir la familia, el estado y la sociedad en general.

El caso de Santa Lucía se puede interpretar desde el punto de vista del mayor acceso a mejores condiciones económicas y sociales, que podría estar detrás de la poca iniciativa por cuestionar aquello que les genera seguridad, ya sea por el temor a desestabilizar su sistema familiar o su propia estabilidad personal, pues recordemos que todo cambio lleva consigo crisis y conflictos que de acuerdo a su manejo, tienden a reorganizar o fracturar el sistema familiar. Si observamos la cotidianidad de los espacios socializadores de estos(as) jóvenes encontramos que por lo regular alternan sus actividades escolares con el gimnasio, la banda de música, el club deportivo, etc. además de la red de amigos(as) y de familia, que les posibilitan otras opciones de vida y una adecuada utilización del tiempo libre.

Las reflexiones contenidas en este articulo, buscan ir mas allá del plano académico, pretendemos con estas líneas poder incidir en la sensibilización de actores sociales y políticos frente al tema, y en la concepción de nuevas formas de relación intrafamiliar e intergeneracional a través de acciones formativas, preventivas y de orientación en espacios como la familia, la escuela, clubes juveniles, instituciones religiosas con acción social, entre otros. Por ello sigue siendo una apuesta no acabada del grupo de Investigación.

\section{BIBLIOGRAFIA}

BADINTER, Elizabeth. (1993) XY, La Identidad Masculina, Grupo editorial Norma. Elizabeth. (1991) ¿Existe el Instinto Maternal? Historia del amor maternal, siglos XVIII al XX, $\overline{\text { ediciones }}^{\prime}$ Paidós.

CALVO Gloria y CASTRO Yolanda. (1995) La Familia en Colombia, Estado del Arte 19980-1994. Vol. I. Ministerio de Salud, ICBF y Consultores Educativos Especializados CEE. Bogotá.

GARCIA-MINA, Ana. (2003) Desarrollo del Género en la Masculinidad y la Feminidad. Narcea S.A. de Ediciones. Madrid, Parte 4.

HOPENHAYN, Martín. (2004) La Juventud en Iberoamerica, Tendencias y Urgencias, CEPAL (Comisión Económica para América Latina y el Caribe) Naciones Unidas, Organización Iberoamericana de la Juventud, Santiago de Chile.

JIMENEZ ZULUAGA, Blanca Inés. (2003) Conflicto y Poder en Familias con Adolescentes: Medellín y Cartagena. Universidad de Antioquia, Centro de Investigaciones Sociales y Humanas, y Fundación para el Bienestar Humano.

KOPPITZ Elizabeth M. (1991) Evaluación Psicológica de los dibujos de la figura Humana por alumnos de educación media, editorial el manual moderno S. A. de C.V. México, D. F. , Santa Fè de Bogotá 
MORAD de Martínez, María del Pilar. (2002) Familias: Espacios con posibilidad de construir y reconstruir ideas de equidad entre los géneros. Revista Palobra $N^{\circ} 3$, Universidad de Cartagena, Facultad de Ciencias Sociales y Educación.

. (2000) La Construcción Socio-Cultural de la Maternidad y la paternidad en Cartagena de indias. Revista Palobra $\mathrm{N}^{\circ} 1$, Universidad de Cartagena, Facultad de Ciencias Sociales y Educación.

MUCCHIELLI, Alex. (1996) Diccionario de Métodos Cualitativos en Ciencias Humanas y Sociales. Editorial Síntesis, Villahermosa, Madrid.

PIÑA, Carlos. (1978) La construcción del Si mismo en el Relato Autobiográfico. Revista paraguaya de Sociología. Año $25 \mathrm{~N}^{\circ} 71$.

PUYANA V., Yolanda (Compiladora). (2003) Padres y madres en cinco ciudades colombianas, cambios y permanencias. CONETS, Universidad Nacional, Universidad del Valle, UNAB, Universidad de Cartagena y Universidad de Antioquia.

y Y ROBLEDO, Ángela Inés (compiladoras). (2000) Ética: Masculinidades y feminidades. Facultad de Ciencias Humanas - Colección CES Universidad Nacional.

(2000) Como se convierten en Mujeres las niñas del Norte de Bolívar: procesos de Socialización y Formación de la identidad. Revista Palobra $N^{\circ} 1$, Universidad de Cartagena, Facultad de Ciencias Sociales y Educación.

SERRANO Amaya, José Fernando. (2002) Ni lo uno ni lo otro: la singularidad de lo Juvenil. En Revista Nómadas $\mathrm{N}^{\circ} 16$ Fundación Universidad Central de Bogotá.

\section{BIOGRAFÍA}

\section{CARMEN CECILIA ALVEAR ROMERO}

Trabajadora Social. Universidad de Cartagena. Especialista en Teorías, Métodos y Técnicas de Investigación Social. Universidad de Cartagena. Jefe Departamento Académico, Facultad de Ciencias Sociales y Educación, Universidad de Cartagena.

\section{ELDA HERAZO DILSON}

Trabajadora Social. Universidad de Cartagena. Especialista en Teorías, Métodos y Técnicas de Investigación Social. Universidad de Cartagena. Docente Facultad de Ciencias Sociales y Educación, Universidad de Cartagena. 